\title{
Novas alternativas terapêuticas para prevenção do câncer labial com produtos à base de extratos naturais com potencial fotoprotetor: uma revisão de literatura
}

\author{
News therapeutic alternatives for lips cancer prevention with \\ products based on natural extracts with photoprotective potential: \\ a review of the literature
}

\author{
Guilherme Pauletto* \\ Raquel Paifer Klarosk* \\ Francisco Zillmer Machado*** \\ Mariana De Carlo Bello*** \\ Carmen Lúcia Rodrigues Macedo ${ }^{* * * *}$ \\ Rubem Beraldo dos Santos ${ }^{* * * * *}$
}

\section{Resumo}

Objetivo: o presente trabalho realiza uma revisão da literatura a respeito do potencial fotoprotetor de extratos naturais contra os efeitos deletérios da radiação solar, dando ênfase à carcinogênese oral e ressaltando os principais tipos de plantas fotoprotetoras nos cenários mundial e nacional. Revisão de literatura: atualmente os extratos de plantas vêm ganhando destaque em pesquisas científicas por serem considerados uma fonte de fotoproteção natural. Vários estudos avaliaram a ação fotoprotetora de produtos naturais contra a radiação ultravioleta, com objetivo de buscar novas opções de plantas medicinais, para evitar o desenvolvimento de doenças relacionadas à radiação ultravioleta. Alguns extratos representam uma fonte segura e eficaz, com condições de contribuir positivamente na prevenção do câncer labial. Entretanto, este campo de estudo é amplo, e muitos biomas regionais com potencial ainda não foram amplamente estudados. Dessa forma, mais pesquisas experimentais e clínicas são necessárias para consolidar a ação de produtos naturais na proteção contra o câncer labial e o câncer de pele. Considerações finais: além dos benefícios fotoprotetores encontrados em extratos de plantas, a utilização de princípios ativos derivados de produtos naturais pode gerar um relevante impacto social, uma vez que estimula a economia da região, promovendo, assim, uma diferenciação no crescimento regional.

Palavras-chave: Extratos vegetais. Neoplasias orais. Plantas medicinais. Radiação solar.

\section{Introdução}

A radiação solar é essencial para a vida na Terra, podendo proporcionar aos seres humanos sensação de bem-estares físico e mental, além de estimular a produção de melanina. Entretanto, ela pode provocar danos à pele humana, dependendo da duração, da frequência de exposição, da intensidade dos raios e da sensibilidade do indivíduo ${ }^{1}$.

A radiação ultravioleta (UV) faz parte do espectro eletromagnético, apresentando comprimentos de onda variáveis entre 200 e 400 nanômetros (nm). É classificada em três categorias, dependendo do ta- 
manho da onda, sendo que: a UVA abrange radiaçoes no comprimento de onda entre $320-400 \mathrm{~nm}$; a UVB, entre $280-320 \mathrm{~nm}$; e a UVC, entre $200-280 \mathrm{~nm}$. Uma vez que a radiação UVC tem o menor comprimento de onda, ela não atinge a superfície terrestre, sendo completamente absorvida pela camada atmosférica da terra. Já a radiação UVA, por apresentar um comprimento de onda mais longo, representa mais de $90 \%$ da radiação solar que atinge a terra e penetra profundamente na epiderme e na derme da pele, podendo causar fotoenvelhecimento prematuro, formação de radicais livres, danos estruturais ao DNA e necrose das células endoteliais. $\mathrm{E}$ a radiação UVB tem um comprimento de onda médio, porém, uma capacidade 1.000 vezes maior de causar queimaduras solares do que a faixa UVA. Atua principalmente na camada epidérmica de células basais da pele, interrompendo o ciclo celular, acarretando fotoenvelhecimento e aumento na produção de radicais livres. Além disso, esta faixa de radiação UV é considerada a responsável por induzir o câncer de pele, como o carcinoma espinocelular e o carcinoma basocelular ${ }^{2}$.

A exposição dos seres humanos à radiação UV, principalmente UVB, por longos períodos, pode produzir várias condições deletérias à saúde ${ }^{3,4}$. Esses danos surgem a partir de diferentes mecanismos. Um exemplo disso é a geração de radicais livres, que, quando em excesso, modificam o DNA, o que leva a perda da integridade celular e a expressão anormal de genes celulares. Os radicais livres são átomos ou moléculas que apresentam um ou mais elétrons desemparelhados em sua órbita externa, condição que os tornam mais reativos e capazes de se ligar a outros átomos ou moléculas e formar suscetivelmente mais radicais livres, como uma reação em cadeia ${ }^{5-7}$.

Usualmente, a população utiliza dois mecanismos para se proteger contra a radiação solar. Um deles compreende barreiras físicas, tais como vestuário, óculos de sol e chapéus. O outro mecanismo engloba a utilização de protetores solares ${ }^{3}$. A primeira linha de defesa são os protetores solares compostos por filtros ultravioletas inorgânicos e orgânicos, em que aqueles também são bloqueadores físicos e estes são absorvedores químicos ${ }^{8}$.

As neoplasias malignas representam uma das principais causas de morbidade e mortalidade em todo o mundo . Em 2009, a Organização Mundial da Saúde sugeriu que a face, as orelhas, o pescoço e os antebraços são as regiões do corpo mais expostas à luz solar, consequentemente, com maior chance de desenvolvimento de câncer ${ }^{10}$. $\mathrm{O}$ câncer bucal é considerado um problema de saúde pública, especialmente em vista do atraso no diagnóstico e dos fatores de riscos sociais da população, tais como consumo de tabaco e álcool, higiene bucal precária e exposição crônica ao sol ${ }^{11}$. Estima-se que mais de 90\% das malignidades que afetam a cavidade oral dizem respeito ao carcinoma espinocelular ${ }^{12}$. Dessa forma, o Programa Global de Saúde Bucal da Organização Mundial da Saúde (OMS), por meio de sistemas globais de vigilância, está empenhado em capacitar os países para prevenção do câncer bucal, realizando troca de informações, de experiências e abordagens integradas para prevenção e promoção da saúde ${ }^{9}$.

A compreensão dos efeitos nocivos da radiação solar UV sobre a pele tem desencadeado inúmeras pesquisas, que buscam avaliar a capacidade de os compostos naturais absorverem a radiação, protegendo assim a pele contra os efeitos deletérios dos raios UV $\mathrm{UV}^{4}$. Filtros naturais são mais seguros e eficientes, quando comparados aos filtros sintéticos, características essas que estimulam mais pesquisas científicas sobre o assunto ${ }^{13}$.

Considerando o referencial teórico apresentado, o objetivo do presente trabalho é realizar uma revisão de literatura a respeito do potencial fotoprotetor de extratos naturais contra os efeitos deletérios da radiação solar, dando ênfase à carcinogênese oral e ressaltando os principais tipos de plantas fotoprotetoras nos cenários nacional e mundial.

\section{Métodos}

A pesquisa foi realizada nas bases de dados Google Acadêmico, SciELO e PubMed, utilizando as seguintes palavras-chave: radiação ultravioleta, efeitos da radiação solar, plantas, câncer bucal, fotoproteção, extratos naturais, plants and câncer, plants and photoprotection, oral cancer treatment. Foram selecionados ao todo 33 artigos, sendo 27 em língua inglesa, 5 em língua portuguesa e 1 em língua espanhola, que foram escolhidos pela relevância ao tema. O período de pesquisa englobou publicações de 1994 a 2017.

\section{Revisão da literatura}

\section{Extratos naturais com potencial fotoprotetor no cenário mundial}

Extratos vegetais são preparações líquidas ou em pó, obtidas da retirada do princípio ativo dos vegetais por diversas metodologias, com a finalidade de conseguir formas terapêuticas mais adequadas para o manuseio a administração $0^{14}$. Atualmente, os extratos de plantas vêm ganhando destaque em pesquisas científicas por serem considerados uma fonte de fotoproteção natural ${ }^{3,15}$.

Plantas presentes em regiões de alta altitude têm um maior potencial fotoprotetor, uma vez que estão expostas a maiores níveis de radiação solar, o que, consequentemente, ocasiona o desenvolvimento de uma resposta química adaptativa das plantas, que as protege contra a agressão dessa radiação ${ }^{3}$. 
Vários estudos avaliaram a ação fotoprotetora de produtos naturais contra a radiação UV, com objetivo de evitar danos a células e tecidos ${ }^{4}$. Em 1997, pesquisas da indústria farmacêutica Cantabria, na Espanha, tinham como objetivo criar formulações a partir de produtos naturais que detinham a capacidade de fotoproteção contra a radiação UV. No estudo, foram avaliados as folhas e os rizomas de uma samambaia do gênero Polypodium. O extrato da planta foi incorporado nas formulações farmacêuticas para aplicação tópica na forma de gel e para administração oral. Observou-se que, quando aplicada topicamente, a solução teve o efeito retardado pela reação de foto-oxidação com o pigmento de melanina já presente na pele, demorando, assim, mais tempo para atingir o efeito desejado; e, quando administrado por via oral, o efeito fotoprotetor máximo foi atingido entre 3 e 24 horas após a ingestão ${ }^{16}$.

Em 2001, pesquisas do laboratório Serobiologiques, na França, avaliaram extratos aquosos ou hidroalcoólicos associados à espécie Adansonia digitata, para verificar a capacidade de capturar e neutralizar radicais livres. Observou-se que o uso de tal combinação ocasiona uma redução na lipoperoxidação induzida pela radiação UVA nos fibroblastos e prostaglandinas e também diminui o dano celular induzido nos queratinócitos, gerado pela radiação UVB. Dessa forma, a combinação apresenta potencial fotoprotetor contra os danos causados pela radiação solar, abrangendo tanto a faixa UVA quanto a UVB ${ }^{17}$.

Em 2002, composições combinadas de extratos vegetal e marinho foram patenteadas pelo pesquisador Olson Bengt Krister, na Dinamarca. O extrato vegetal compreendia o extrato de semente de uva e o extrato de tomate, ao passo que o extrato marinho se referia à cartilagem de animais marinhos, como tubarão, baleia, golfinho, molusco, entre outros. Notou-se que a combinação desses extratos resultou numa composição eficaz para aumentar a síntese de colágeno na pele, bem como reduziu significativamente a oxidação mediada por radicais livres dentro da derme. Portanto, a combinação apresentou um excelente efeito antioxidante e inibidor de radicais livres, evitando, dessa forma, o envelhecimento da pele ${ }^{18}$.

Em 2003, a indústria farmacêutica Skinceuticals, nos Estados Unidos, realizou pesquisas com extrato da folha de oliveira. Observou-se que esse extrato, combinado com outros produtos, como ácido L-ascórbico, $\alpha$-tocoferol e retinol, tem um ótimo efeito protetor contra a radiação $\mathrm{UV}^{19}$.

Em 2007, pesquisas de Howard Murad avaliaram a ação do extrato de Durio zibethinus, concluindo que esse composto é útil na prevenção da perda de água corporal, do surgimento de rugas e da perda de elasticidade da pele, características associadas ao envelhecimento biológico e ao fotoenvelhecimen$\mathrm{to}^{20}$.
Em 2010, foi patenteada uma composição cosmética para a proteção da pele contra a radiação solar a partir de extratos de flores de Magnolia sieboldii. Tal extrato proporcionou um efeito fotoprotetor que inibiu a morte de queratinócitos e fibroblastos, causada pela radiação solar, além de inibir a produção de colagenase ${ }^{21}$.

Niculae et al. ${ }^{22}$ (2004) criaram formulações cosméticas seguras com potencial fotoprotetor contra a radiação solar. Foram utilizadas grandes quantidades de óleo de farelo de arroz e óleo de semente de framboesa com baixas concentrações de filtros solares sintéticos contra as radiações UVA e UVB, como butil-metoxidibenzoilmetano (BMDBM) e octocrileno (OCT), tendo-se verificado um efeito antioxidante, ou seja, uma alta capacidade para eliminar radicais livres. O estudo demonstrou um avanço significativo nas áreas de nanotecnologia e cosméticos, em função do desenvolvimento de formulações cosméticas mais seguras, com ampla eficácia antioxidante e fotoprotetora, devido à existência de um alto teor de óleos vegetais nanoestruturados combinados com uma pequena quantidade de filtros UV sintéticos na mesma fórmula.

Bulla et al. ${ }^{23}$ (2005) avaliaram o potencial fotoprotetor do extrato bruto de folhas de Schinus terebinthifolius, uma planta rica em compostos fenólicos. Na pesquisa, notou-se que o extrato tem potencial fotoprotetor, apresenta propriedades antioxidantes e pode oferecer uma nova oportunidade de prevenção das doenças causadas pela radiação UV, como o fotoenvelhecimento e o câncer de pele.

Pesquisas realizadas por Pérez-Sánchez et al. ${ }^{24}$ (2016) avaliaram os efeitos protetores do principal composto fenólico do extrato de bálsamo de limão, o ácido rosmarínico, contra danos induzidos pela radiação UVB em queratinócitos humanos. Foi observado que tal composto fenólico presente no extrato aumenta significativamente a sobrevivência dos queratinócitos humanos após a radiação UVB, diminui significativamente a produção de radicais livres intracelulares e reduz o dano induzido pela radiação UV ao DNA. O estudo sugere que o extrato de bálsamo de limão pode ser utilizado no desenvolvimento de fotoprotetores orais ou tópicos contra danos cutâneos induzidos pela radiação UVB.

O Polypodium leucotomos, planta nativa da América Central e do Sul, está disponível comercialmente em muitas partes do mundo em formulações tópicas para proteção solar. Estudos com formulações orais mostraram que, quando tal extrato é administrado por via oral em detrimento das formulações tópicas, existe um maior potencial fotoprotetor contra a radiação $\mathrm{UV}^{25,26}$.

A nicotinamida é uma forma amida da vitamina B3 amplamente disponível como suplemento dietético oral, que demonstrou prevenir a depleção intracelular induzida pela radiação UV ao trifosfato de adenosina, estimulando a energia celular e prevenindo a imunossupressão $0^{15,25}$. Logo, a nicotinamida, 
que é encontrada em uma gama de alimentos, como carnes de frango, porco e peixe, cogumelos, amendoim, nozes, sementes, cereais, tomate, batata, cenoura, feijão, ervilha, arroz, entre outros, quando administrada em formulações orais, proporciona elevado nível de fotoproteção ${ }^{15}$.

Extratos vegetais da folha de carambola, do lótus da neve, da casca do pinheiro marítimo e extratos do gênero Solanum, bixa orellana, eucommia e Laserpitium siler também funcionam como fotoprotetores naturais, apresentando resistência às radiações UVA e UVB, e, portanto, são utilizados como ingredientes ativos na fabricação de cosméticos e medicamentos para a pele contra o envelhecimento ${ }^{4}$.

\section{Extratos naturais com potencial fotoprotetor oriundos de plantas brasileiras}

O Brasil é um país rico em fontes naturais, sendo o Cerrado central brasileiro uma região com mais de 7000 espécies nativas de plantas vasculares ${ }^{27}$. Devido a essa diversidade, o mercado de ciência e cosméticos tem desenvolvido produtos com maior porcentagem de componentes naturais, buscando explorar a biodiversidade brasileira ${ }^{10,27}$.

No Brasil, pesquisas com produtos naturais que buscam um fotoprotetor em potencial, com princípios ativos orgânicos, são respaldadas pela Portaria $\mathrm{n}^{-}$2.960, de 09 de dezembro de 2008, que aprova o Programa Nacional de Plantas Medicinais e Fitoterápicos e incentiva a sua utilização no Sistema Único de Saúde (SUS). Todos esses produtos são avaliados pela Agência Nacional de Vigilância Sanitária (Anvisa), segundo a Resolução RDC nº 47, de 16 de março de 2006, que permite maior segurança da utilização dessas substâncias pela população ${ }^{10}$.

Tal tema tem sido cada vez mais pesquisado no Brasil, com o intuito de encontrar novas fontes naturais que apresentem potencial fotoprotetor e não demonstrem efeitos adversos ${ }^{27}$. O própolis produzido por abelhas a partir da resina de plantas é de origem estrangeira, entretanto, no Brasil há várias cultivações, que nos permitem usufruir de seus benefícios $^{28}$. Ele, além de apresentar grande importância na agricultura, tem sido frequentemente utilizado na medicina tradicional, pois apresenta ações antioxidante, imunoestimulante, anti-inflamatória, antisséptica, antimicótica, bacteriostática, anestésica e anticancerígena. Outro foco de pesquisa recente é a sua capacidade de fotoproteção solar. $\mathrm{O}$ extrato de própolis verde apresenta componentes ativos, como flavonoides, explicando a alta atividade antioxidante e de fotoproteção contra UVA e UVB. Além disso, quando comparado a protetores sintéticos, o própolis é mais eficaz ${ }^{28,29}$.

Em 2012, foi realizado um estudo para avaliar a capacidade antioxidante da soja Glycine $\max L$.
Merrill, da família Leguminosae. Foi comparado o extrato bruto da soja com o extrato bruto de soja fermentada, dissolvidos em água ou etanol. Em ambos os extratos, observou-se uma grande quantidade de isoflavonoides, porém o extrato bruto de soja dissolvida em água apresentou maiores atividade antioxidante e proteção contra radiação $\mathrm{UVB}^{30}$.

Siraichi et al. ${ }^{31}$ (2013) realizaram uma pesquisa sobre a ação de fotoproteção da espécie Arrabidaea chica que pertence à família Bignoniaceae, encontrada na América do Sul, em países como México e Brasil. No Brasil, tal espécie é mais comum na região amazônica. Essa planta é reconhecida por suas propriedades anti-inflamatórias e adstringentes. Notou-se que o extrato bruto de Arrabidaea chica apresenta um tempo de absorção de 150 minutos e, após esse período, permanece por 180 minutos na pele, sendo bastante satisfatório, pois é semelhante à absorção de filtros solares comerciais. Além disso, a planta é rica em antocianinas, flavonoides e taninos, que apresentam alta capacidade de absorver a radiação UVA e UVB. Portanto, o extrato é altamente indicado para compor formulações de fotoprotetores, pois é natural e livre de compostos inorgânicos.

Elias et al. ${ }^{32}$ (2014) avaliaram a atividade citotóxica de extratos de plantas do Cerrado brasileiro associados à radioterapia em células de carcinoma de cabeça e pescoço. Foram avaliadas as folhas de Erythroxylum suberosum A. St.-Hil., E. Daphinites (Mart.), E. subrotundum A.St.-Hil. (Erythroxylaceae), Pouteria torta (Mart.) Radlk. e Pouteria ramiflora (Mart.) Radlk. (Sapotaceae). Observou-se que alguns extratos são mais citotóxicos que outros. Os extratos que apresentaram menor potencial de destruição dessas células foram associados à radioterapia, outros extratos foram utilizados antecedendo a radioterapia, já os com citotoxicidade grave, como $E$. Suberosum, apresentaram resultados positivos, isto é, apresentaram destruição das células de carcinoma, quando administrados como único tratamento. Dessa forma, pode-se sugerir que células cancerígenas de cabeça e pescoço são sensíveis aos extratos de plantas, e, quando utilizadas corretamente, tornam-se um potencializador da eficiência da radioterapia.

Martins et al. ${ }^{33}$ (2016) descreveram as atividades antioxidantes e fotoprotetoras de seis espécies de plantas encontradas no estado do Pará, Brasil. Estas plantas foram: Aniba canelilla (casca-preciosa), Brosimum acutifolium Huber (mururé), Dalbergia monetaria Lineu $f$. (verônica), Caesalpinia pyramidalis Tul. (catingueira), Crajiru (Humb. \& Bonpl.) B. Verl. (pariri) e Aspidosperma nitidum Benth (carapanaúba). Todas apresentaram potencial antioxidante pela presença de flavonoides e taninos. Contudo, uma vez que é obrigatório que o Fator de Proteção Solar (FPS) seja igual ou superior a 6 para ser aprovado para rotulagem, apenas o extrato $D$. Monetaria cumpriu o requisito. 


\section{Discussão}

O nível de radiação UV que atinge a superfície terrestre aumentou drasticamente nos últimos anos. Esse fenômeno, além da sobre-exposição da pele à radiação $\mathrm{UV}$, contribuiu para o aumento constante nos distúrbios relacionados à pele em seres humanos ${ }^{29}$. Tradicionalmente, considera-se que a proteção contra os efeitos prejudiciais da radiação solar pode ser obtida principalmente pelo uso de protetores solares tópicos que refletem a luz solar ou pelo uso de vestimentas específicas ${ }^{3,15}$. Segundo Lim et al. ${ }^{25}$ (2016), os protetores solares tradicionais tópicos proporcionam proteção eficaz contra o eritema, mas não são significativamente eficazes contra a inibição da geração de espécies reativas de oxigênio que provocam um estresse oxidativo celular na pele depois da exposição à radiação ultravioleta. Já os fármacos orais demonstram ser eficientes tanto na proteção ao eritema como na inibição da formação de espécies reativas de oxigênio. Nos dias atuais, existe um interesse crescente na utilização de fármacos oriundos de extratos de plantas administrados por via(s) oral e/ou subcutânea, com potencial para proporcionar proteção contra a exposição à radiação solar e, consequentemente, reduzir os efeitos prejudiciais. Esses agentes são diferentes dos protetores solares sintéticos no que diz respeito ao seu mecanismo de ação, à sua eficácia e aos benefícios de utilização. Verificou-se que vários agentes naturais administrados por vias oral e subcutânea, se comparados aos protetores solares, têm maior potencial de reduzir a gravidade de uma queimadura solar e diminuir a fotossensibilidade ${ }^{25}$.

Niculae et al. ${ }^{22}$ (2014) observaram que os óleos de farelo de arroz e de semente de framboesa, quando misturados com baixas concentrações de filtros solares sintéticos, têm potencial fotoprotetor contra a radiação solar, englobando tanto a faixa UVA quanto a UVB. Já Samruan et al..$^{30}$ (2012), em estudo desenvolvido a partir do extrato da soja, observaram fotoproteção apenas contra a radiação UVB. Segundo Sawean et al. ${ }^{29}$ (2015), o própolis apresenta ação antioxidante, anti-inflamatória e anticancerígena, capacidade de fotoproteção solar, entre outras propriedades relevantes. Esses achados são consolidados pelos resultados de alguns estudos, como o de Reis et al..$^{28}$ (2009), em que foi visto que o extrato de própolis verde apresenta alta taxa de absorção de raios UV pela presença de componentes ativos, como os flavonoides. Seguindo essa linha de raciocínio, Pathak et al. ${ }^{16}$ (1997) demonstraram que fármacos desenvolvidos a partir da incorporação de extratos de plantas, quando administrados por via oral, podem proporcionar níveis adicionais de fotoproteção, se comparados a formulações tópicas. Em revisões de literatura, Chen et al..$^{15}$ (2014), Lim et al. ${ }^{25}$ (2016) e Gonzalez et al. ${ }^{26}$ (2010) também relatam tal achado. Chen et al. ${ }^{15}$ (2014) concluíram que essas substâncias orais derivadas de extratos naturais e administradas junto com a ingestão de alimentos, ou como suplementos dietéticos, também aumentam a produção de trifosfato de adenosina (ATP), inibem a produção de espécies reativas do oxigênio e diminuem a produção de prostaglandina E2 (PGE2), ajudando, consequentemente, a reduzir o dano induzido pela luz solar em humanos. Logo, os suplementos fotoprotetores orais naturais estão sendo desenvolvidos e podem ocupar um papel relevante na prevenção contra o câncer.

No entanto, conforme Violante et al. ${ }^{27}$ (2009), embora a maioria dos estudos com extratos de plantas e com componentes naturais tem apresentado resultados positivos referente à proteção às radiações ultravioletas, existem outros em que, mesmo evidenciando a presença de componentes antioxidantes e de antienvelhecimento nos extratos naturais, a presença dessas propriedades não é suficiente para caracterizar o extrato ou o componente como um fotoprotetor orgânico. Portanto, para um protetor solar ser considerado eficaz em sua atividade fotoprotetora, ele depende da relação entre a absorção de energia, a concentração do extrato, o intervalo de absorção e o comprimento de onda em que ocorre a absorção máxima. Esse fato corrobora com os achados da pesquisa realizada por Martins et $a .^{33}$ (2016), que observou que, das seis espécies de plantas estudadas, apenas uma apresentou efeito fotoprotetor, embora todas apresentassem potencial antioxidante.

Extratos de plantas representam uma fonte rica de produtos seguros e eficazes ${ }^{13}$, dessa forma, cada vez mais novas opções de plantas medicinais vêm sendo estudadas para o tratamento de diversas doenças, contribuindo positivamente com a terapêutica moderna ${ }^{14}$. O Brasil continua procurando descobrir mais sobre sua biodiversidade, incentivando a busca por esses produtos, a fim de melhorar a saúde da população e proporcionar o aumento da economia local ${ }^{10}$. Nesse contexto, são necessários estudos experimentais de plantas de diferentes biomas brasileiros, por meio de pesquisas básicas, como a avaliação da absorbância de extratos naturais in vitro e, depois, estudos in vivo, a fim de verificar a fotoproteção e a eficácia. A viabilidade econômica de tais produtos pode contribuir para o desenvolvimento de produtos seguros, mais baratos, que valorizam a biodiversidade brasileira.

\section{Considerações finais}

A utilização de produtos naturais tem sido frequente pela população mundial, e isso não é diferente para os filtros solares, já que o raio UV gera efeitos deletérios ao corpo humano. Com isso, as indústrias farmacêuticas e as universidades têm desenvolvido estudos e pesquisas acerca de novas fórmulas naturais e com potencial de proteção contra a exposição solar. 
Entre tantos extratos naturais, os mais relatados são: a antocianina, a quercetina, a apigenina, a genisteína, os flavonoides, os taninos, as antraquinonas, os alcaloides e os polifenóis, os quais apresentam efeitos anti-inflamatório, anticarcinogênico e antioxidantes e capacidade de proteção contra a radiação UV.

Além dos efeitos benéficos contra a radiação UV encontrados nos extratos de plantas, a utilização de produtos naturais pode gerar um relevante impacto social, pois, ao se desenvolver fotoprotetores baseados em princípios ativos naturais, estimula-se a economia das regiões estudadas, propiciando, assim, uma diferenciação no crescimento regional. Contudo, este campo de estudo é amplo, e muitos biomas regionais com potencial ainda não foram largamente estudados. Dessa forma, mais pesquisas experimentais e clínicas são necessárias para consolidar a ação de produtos regionais naturais na proteção contra câncer labial e câncer de pele.

\section{Agradecimento}

Os autores agradecem à Direção de Pesquisa da Pró-Reitoria Acadêmica da Universidade Luterana do Brasil, por meio do programa de pesquisa RIT Saúde, pelo suporte prestado a este trabalho.

\section{Abstract}

Objective: the present work aims to reviewed the literature on the potential photoprotector of natural extracts against the deleterious effects of solar radiation, emphasizing oral carcinogenesis and highlighting the main types of photoprotective plants at world and national level. Literative review: currently plant extracts have been gaining prominence in scientific research because they are considered a source of natural photoprotection. Several studies have evaluated the photoprotective action of natural products against ultraviolet radiation, aiming to find new options for medicinal plants to avoid the development of diseases related to ultraviolet radiation. Some extracts represent a safe and effective source, with conditions to contribute positively in the prevention of oral cancer. However, this field of study is broad and many potential biomes with potential have not yet largely been studied. In this way, more researches experimental and clinical are needed to consolidate the action of natural products in protection against cancer of lips and skin. Final considerations: in addition to the photoprotective benefits found in plant extracts, the use of active ingredients derived from natural products can generate a significant social impact, since it stimulates the region's economy, thus generating a differentiation in regional growth.

Keywords: Medicinal plants. Oral neoplasms. Plant extracts. Solar radiation.

\section{Referências}

1. Flor J, Davolos MR, Correa MA. Protetores Solares. Quim Nova 2007; 30:153-8.

2. Svobodová A, Psotová J, Walterová D. Natural phenolics in the prevention of uv-induced skin damage. A review. Biomed Papers 2003; 147(2):137-45.

3. Mejía-Giraldo JC, Henao-Zuluaga K, Gallardo C, Atehortúa L, Puertas-Mejía MA. Novel In Vitro Antioxidant and Photoprotection Capacity of Plants from High Altitude Ecosystems of Colombia. Photochem Photobiol 2016; 92:150-7.

4. Serafini MR, Guimarães AG, Quintans JSS, Araújo AAS, Nunes PS, Quintans-Júnior LJ. Natural compounds for solar photoprotection: a patent review. Expert Opin Ther Pat 2014; 25(4):467-78.

5. Arslan A, Orkun S, Aydin G, Keles I, Tosun A, Arslan M et al. Effects of ovariectomy and ascorbic acid supplement on oxidative stress parameters and bone mineral density in rats. Libyan J Med 2011; 6:5965.

6. Bora NS, Mazumder B, Chattopadhyay P. Prospects of topical protection from ultravioleta radiation exposure: a critical review on the juxtaposition of the benefits and risks involved with the use of chemoprotective agents. J Dermatolog Treat $2017 ; 18: 1-13$.

7. Halliwell B. Free radicals, antioxidants, and human disease: curiosity, cause, or consequence. The Lancet 1994; 344:721-4.

8. Balogh TS, Velasco MVR, Pedriali CA, Kaneko TM, Baby AR. Ultraviolet radiation protection: current available resources in photoprotection. An Bras Dermatol 2011; 86(4):732-42.

9. Petersen PE. Oral cancer prevention and control - The approach of the World Health Organization. Oral Oncol $2009 ; 45: 454-60$

10. Polonini HC, Raposo NRB, Brandão MAF. Fotoprotetores naturais como instrumento de ação primária na prevenção do câncer de pele. Rev APS 2011; 14(2):216-23.

11. Wood NH, Khammissa R, Meyerov R, Lemmer J, Feller L Actinic Cheilitis: A Case Report and a Review of the Literature. Eur J Dent 2011; 5:101-6.

12. Warnakulasuriya S. Global epidemiology of oral and oropharyngeal cancer. Oral Oncol 2009; 45:309-16.

13. Velasco MVR, Balogh TS, Pedriali CA, Sarruf FD, Pinto CASO, Kaneko TM, et al. Associação da Rutina com p-Metoxicinamato de Octila e Benzofenona-3: avaliação in vitro da eficácia fotoprotetora por espectrofotometria de refletância. Lat Am J Pharm 2008; 27:23-7.

14. Marques LC. Preparação de extratos vegetais. JBF 2005; 3(2):74-6.

15. Chen AC, Damian DL, Halliday GM. Oral and systemic photoprotection. Photodermatol Photoimmunol Photomed 2014; 30:102-11.

16. Pathak MA, Gonzales S, Fitzpatrick TB. Polypodium extract as photoprotectant. US005614197A; 1997.

17. Pauly G. Use of an extract of the genus Adansonia US006274123B1; 2001.

18. Olson BK. Combined marine and plant extract compositions. US 20020012714A1; 2002.

19. Pinnell SR, Omar MM. Olive leaf extraction method and formulations containing olive leaf extract. US 20030152656A1; 2003.

20. Murad H. Pharmaceutical and dermatocosmetic compositions comprising extract of durio zibethinus. WO2007064966A2; 2007. 
21. Lee GT, Lee JN, You YK, Lee SJ, Lee KK. Cosmetic composition for protecting skin against uv light and wrinkle improvement containing the extract of Magnolia sieboldii flower extracts. US20100055210A1; 2010.

22. Niculae G, Lacatusu I, Badea N, Stan R, Vasile BS, Meghea A. Rice bran and raspberry seed oil-based nanocarriers with self-antioxidative properties as safe photoprotective formulations. Photochem Photobiol Sci 2014; 13:703-16.

23. Bulla MK, Hernandes L, Baesso ML, Nogueira AC, Bento AC, Bortoluzzi BB et al. Evaluation of Photoprotective Potential and Percutaneous Penetration by Photoacoustic Spectroscopy of the Schinus terebinthifolius Raddi Extract. Photochem Photobiol 2015; 91:558-66.

24. Pérez-Sánchez A, Barrajón-Catalán E, Herranz-López M, Castillo J, Micol V. Lemon balm extract (Melissa officinalis, L.) promotes melanogenesis and prevents UVB-induced oxidative stress and DNA damage in a skin cell model. J Dermatol Sci 2016; 84(2):169-177.

25. Lim HW, Arellano-Mendoza MI, Stengel F. Current challenges in photoprotection. J Am Acad Dermatol 2016; 76(3S1):S91-S99.

26. Gonzalez S, Gilaberte Y, Philips N. Mechanistic insights in the use of a Polypodium leucotomos extract as an oral and topical photoprotective agent. Photochem Photobiol Sci 2010; 9:559-63.

27. Violante IMP, Souza IM, Venturini CL, Ramalho AFS, Santos RAN, Ferrari M. Avaliação in vitro da atividade fotoprotetora de extratos vegetais do cerrado de Mato Grosso. Rev Bras Farmacogn 2009; 19(2A):452-7.

28. Reis GS, Valadão AF, Lima LRP, Moreira ML. Preparación de un protector solar y evaluación de la acción fotoprotectora del propóleo verde del Vale do Aço, Minas Gerais, Brasil. BLACPMA 2009; 8(4):282-8.

29. Saewan N, Jimtaisong A. Natural products as photoprotection. J Cosmet Dermatol 2015; 14:47-63.

30. Samruan W, Oonsivilai A, Oonsivilai R. Soybean and Fermented Soybean Extract Antioxidant Activities. World Acad Sci Eng Technol 2012; 6(12):1134-7.

31. Siraichi JTG, Pedrochi F, Natali MRM, Ueda-Nakamura T, Dias Filho BP, Bento AC et al. Ultraviolet (UVB and UVA) Photoprotector Activity and Percutaneous Penetration of Extracts Obtained from Arrabidaea chica. Appl Spectrosc 2013; 67(10):1179-84.

32. Elias ST, Borges GA, Amorim DA, Rêgo DF, Simeoni LA, Silveira $D$ et al. Radiation induced a supra-additive cytotoxic effect in head and neck carcinoma cell lines when combined with plant extracts from Brazilian Cerrado biome. Clin Oral Invest 2014; 19(3):637-46.

33. Martins FJ, Caneschi CA, Vieira JLF, Barbosa W, Raposo NRB. Antioxidant activity and potential photoprotective from amazon native flora extracts. J Photochem Photobiol B 2016; 161:34-9.

Endereço para correspondência:

Mariana De Carlo Bello

Avenida Medianeira, 1688, ap. 802, Centro

CEP 97060-002, Santa Maria, RS, Brasil

Telefone: (55) 99159-5503

E-mail: maridcbello@yahoo.com.br

Recebido: 05/10/17. Aceito: 26/11/17. 